\title{
Toxic leadership: Effects on job satisfaction, commitment, turnover intention and organisational culture within the South African manufacturing industry
}

\begin{tabular}{|c|c|}
\hline \multicolumn{2}{|c|}{$\begin{array}{l}\text { Authors: } \\
\text { Amelda Paltu }{ }^{1} \text { (D) } \\
\text { Marissa Brouwers }\end{array}$} \\
\hline \multicolumn{2}{|c|}{$\begin{array}{l}\text { Affiliations: } \\
{ }^{1} \text { School of Human Resource } \\
\text { Sciences, Faculty of Economic } \\
\text { and Management Sciences, } \\
\text { North-West University, } \\
\text { Potchefstroom, South Africa }\end{array}$} \\
\hline \multicolumn{2}{|c|}{$\begin{array}{l}\text { Corresponding author: } \\
\text { Marissa Brouwers, } \\
\text { marissa.brouwers@nwu.ac.za }\end{array}$} \\
\hline \multicolumn{2}{|c|}{$\begin{array}{l}\text { Dates: } \\
\text { Received: } 10 \text { Feb. } 2020 \\
\text { Accepted: } 26 \text { May } 2020 \\
\text { Published: } 13 \text { July } 2020\end{array}$} \\
\hline \multicolumn{2}{|c|}{$\begin{array}{l}\text { How to cite this article: } \\
\text { Paltu, A., \& Brouwers, M. } \\
\text { (2020). Toxic leadership: } \\
\text { Effects on job satisfaction, } \\
\text { commitment, turnover } \\
\text { intention and organisational } \\
\text { culture within the South } \\
\text { African manufacturing } \\
\text { industry. SA Journal of } \\
\text { Human Resource } \\
\text { Management/SA Tydskrif vir } \\
\text { Menslikehulpbronbestuur, } \\
\text { 18(0), a1338. https://doi.org/ } \\
\text { 10.4102/sajhrm.v18i0.1338 }\end{array}$} \\
\hline \multicolumn{2}{|c|}{$\begin{array}{l}\text { Copyright: } \\
\text { (C) 2020. The Authors } \\
\text { Licensee: AOSIS. This } \\
\text { is licensed under the } \\
\text { Creative Commons } \\
\text { Attribution License. }\end{array}$} \\
\hline \multicolumn{2}{|l|}{ Read online: } \\
\hline 口: & $\begin{array}{l}\text { Scan this QR } \\
\text { code with your } \\
\text { smart phone or } \\
\text { mobile device } \\
\text { to read online. }\end{array}$ \\
\hline
\end{tabular}

Orientation: The impact of toxic leadership on employees and organisations has only recently become the focus of certain research studies.

Research purpose: The general objective of this research was to investigate the relationship between toxic leadership, job satisfaction, turnover intention and commitment. The aim further was to test whether organisation culture mediates the relationship between toxic leadership and certain job outcomes such as job satisfaction, turnover intention and commitment.

Motivation for the study: Currently, no knowledge is available on the relationships between toxic leadership and job outcomes within the context of South African manufacturing organisations. Therefore, this study provides South African organisations and researchers with an insight into such a relationship and the mentioned mediation of organisational culture in the process.

Research approach/design and method: A cross-sectional research design with a sample size of $N=600$ manufacturing employees was used. Product-moment correlations, multiple regression and structural equation modelling were used.

Main findings: The test results returned both direct and indirect effects for all the relationships, which indicated only partial mediation in all the tested relationships.

Practical/managerial implications: The results provided organisations' insight into the possible consequences of toxic leadership on employees and the organisations' culture.

Contribution/value-add: The improved understanding of toxic leadership and the relationship with certain job outcomes contributes to the body of knowledge on both the theory of toxic leadership and on employees' experience of such leadership styles in the work environment.

Keywords: toxic leadership; job satisfaction; organisation commitment; turnover intention; organisational culture; correlations; mediation; regression; structural equation.

\section{Introduction}

Leadership contributes significantly to an organisation's success or failure (Lok \& Crawford, 2003). According to Rasid, Manaf and Quoquab (2013), the capability of a leader to lead and motivate employees should not be disregarded. However, in recent years, there has been a rise in toxic leadership styles within organisations (Mehta \& Maheshwari, 2013), and Veldsman (2012) argued that as many as three out of 10 leaders may manifest such a toxic style of leadership. Veldsman (2012) indicated that toxic leadership threatens the well-being of both individuals and organisations, and this creates an urgent need to understand the nature and evolution of toxic leadership and the organisations involved. Through an initial research into toxic leadership, several key themes have emerged. These are the following: toxic leaders are harmful or abusive (Lipman-Blumen, 2005), tend to micromanage (Mehta \& Maheshwari, 2013), are unpredictable (Schmidt, 2008), display narcissistic tendencies (Schmidt, 2008), show a lack of integrity and cause divisiveness (LipmanBlumen, 2005). However, minimal literature is available on the influence of toxic leadership on organisations as well as the individuals who work in these organisations (Leet, 2011).

The manufacturing sector currently contributes around $13.2 \%$ of the gross domestic product (GDP) and is the fourth largest sector in the South African economy, as reported in March 2019 (IDC 
[Industrial Development Corporation], 2019). Furthermore, according to the IDC, the total number employed at the end of the last quarter of 2018 was $1.21 \mathrm{~m}$ people (IDC, 2019). The sector has seen a decline of $1.4 \%$ over the last 6 years, increasing the pressures that managers have to deal with in terms of cost, electricity supply, skills shortages and productivity levels (IDC, 2019). As the manufacturing industry is labour-intensive, it is important to recognise the behaviours of leaders that can be detrimental not only to the organisation but also to the performance of the employees (Mehta \& Maheshwari, 2013). Therefore, it is important to investigate the prevalence and presence of toxic leadership in the manufacturing industry.

Whilst positive leadership styles are correlated with good organisational results, certain negative leadership styles have harmful effects on employees and the work environment (Akca, 2017). In this regard, results from a recent survey by Life Meets Work Consulting indicated that as many as $56 \%$ of employees were currently working for a toxic leader whose behaviour was creating an unhealthy work environment (Lazarczyk, 2017). Several studies investigated negative leadership styles from which the theme of toxic leadership has emerged (e.g. Kusy \& Holloway, 2009; Lipman-Blumen, 2005; Mehta \& Maheshwari, 2014; Schmidt, 2008, 2014).

These initial studies into toxic leadership indicate that this concept exists in numerous organisations today. Thus, scores of employees have been exposed to leaders and managers who display toxic behaviour styles (Mehta \& Maheswari, 2014). However, evident from the initial studies was the insight that toxic leaders may be highly competent and effective in their jobs but help cause an unhealthy climate among their subordinates and peers, with the consequences of their actions reaching further than merely a few individuals (Tavanti, 2011). Toxic leadership also appeared to be a leadership style in its own right, not merely defined as the lack of effective leadership (Schmidt, 2008).

Through the above-mentioned studies, toxic leaders have been broadly referred to as individuals who, through their destructive behaviour, inflict serious and enduring harm on individuals, groups, organisations, communities and even nations that they lead (Lipman-Blumen, 2005). According to Mehta and Maheshwari (2013), toxic leaders and their decisions do not only affect the organisation but also every individual with whom they come in contact. Schmidt (2008) agreed that this leadership style has particularly negative consequences for the entire workforce and the organisation as a whole. Organisational outcomes because of toxic leadership include negative effects on a company's performance (Ashforth, 1997), higher turnover intention (Tate, 2009) and a lack of commitment (Weaver \& Yancy, 2010). Webster, Brough, Daly and Myors (2011) found that the articles and books outlining the effects of toxic leadership have a conceptual nature, with limited empirical investigations performed to test the effect on job outcomes. This finding is supported by Schmidt (2014) who emphasised the limited empirical testing on the relationship between toxic leadership and job-related outcomes.

According to Lok and Crawford (2003), there is also a strong correlation between leadership, organisational culture and its effect on organisational commitment and job satisfaction. Sadri and Lees (2001) found that negative organisational culture impedes an organisation's ability to perform. Van der Post, De Coning and Smit (1997) indicated that organisations are 'living entities' that exhibit their own personalities through what is known as 'organisational culture'. This culture in turn gives meaning and direction to the employees (Van der Post et al., 1997) and creates an environment within which the organisation functions (Sempane, Reiger, \& Roodt, 2002). Schein (2004) suggested that the leadership of an organisation and its culture are linked closely, and that senior leaders permeate an organisation's culture with their own personal characteristics by establishing goals, values and norms (Schneider, Goldstein, \& Brent-Smith, 1995). Giberson et al. (2009) asserted that toxic leaders create a toxic culture by changing the content of ideal leadership.

Recent studies on leadership have indicated that organisational culture may have a mediating effect on the relationship between leadership and job outcomes, and that the mediator's influence is stronger than that of the independent variable (Imran, Zahoor, \& Zaheer, 2012; Rasid et al., 2013). Therefore, it is necessary to investigate the influence or the mediating effect of organisational culture between toxic leadership and certain job outcomes, for example, job satisfaction, organisational commitment, organisational culture and turnover intention. Such an investigation is necessary as, to date, no study in South Africa has attempted to measure the mediating effect of organisational culture on toxic leaders.

Furthermore, in South Africa, limited research has been conducted on the topic of toxic leadership as such. An introductory study by Veldsman (2012) centred on introducing and defining the concept. Dladla (2011), Du Toit (2015) and Heine (2013) in South Africa restricted their research to investigating certain aspects of negative leadership, such as unethical behaviour and distrust. It is important to understand whether the phenomenon of toxic leadership is also present in the South African workplace, and if so, what its impact is on employees in those organisations. Thus far, no study in South Africa has attempted to measure toxic leadership and its relationship with the above-mentioned job-related outcomes, as well as its effect on the organisation and its employees. The manufacturing industry in South Africa is currently under pressure to remain competitive, and one of the main reasons for this pressure is inefficient leadership (Ebrahim \& Pieterse, 2016). Therefore, a study of this nature will help the manufacturing industry assess toxic leadership in the industry, as well as contribute to the limited research available on this topic currently. 


\section{Research purpose and objectives}

The general objective of this research was to investigate the relationship between toxic leadership, job satisfaction, turnover intention and organisational commitment. The aim further was to test whether organisational culture mediates the relationship between toxic leadership and certain job outcomes, such as job satisfaction, turnover intention and organisational commitment.

\section{Literature review}

Toxic leadership can and should be universally recognised as a unique set of destructive behaviours or characteristics that negatively impact the subordinate group in a predictable and intentional way (Padilla, Hogan, \& Kaiser, 2007). For the purpose of this study, toxic leadership can be described as a concept that is multidimensional in nature, which compromises various dimensions as outlined by Schmidt (2008). Toxic leadership comprises five dimensions: (1) Abusive supervision refers to a leader's perceived intentionally hostile behaviours towards employees (Dobbs, 2014; Schmidt, 2014), excluding physical contact (Tepper, 2007); (2) Authoritarian leadership attempts to exert excessive authority and control over subordinates (Dobbs, 2014) in such a way that the leaders ultimately control all the work (Schmidt, 2014); (3) Narcissism points to a style driven by arrogance and self-absorption, where self-orientated actions are designed to enhance the self (Dobbs, 2014) but often fails to follow company policies whilst expecting it of employees (Schmidt, 2014); (4) Self-promotion advertises their accomplishments and also take credit for others' work (Dobbs, 2014), blame others and deflect responsibility for mistakes (Schmidt, 2014); and (5) Unpredictability: through their actions, they keep subordinates afraid and watchful (Dobbs, 2014). These leaders act differently when their superiors are around (Schmidt, 2008), and their consistently unpredictable actions eventually cause their subordinates to give up, feeling helpless and powerless to protect themselves (Schmidt, 2014).

\section{Job satisfaction}

Job satisfaction has to do with an individual's perceptions and evaluation of his job, and this perception is influenced by the person's unique circumstances, such as needs, values and expectations. (Buitendach \& Rothmann, 2009, p. 1)

Mehta and Maheshwari (2013) found a statistically significant negative relationship between toxic leadership and job satisfaction. Their findings are supported by Schmidt (2014) who indicated a statistically negative relationship between toxic leadership and job satisfaction on both the individual and group level. Kusy and Holloway (2009), as well as Tepper (2007), concurred that toxic, destructive and dysfunctional leadership behaviour has a negative impact on employees' job satisfaction. Job satisfaction is the most important factor in understanding worker motivation, effectiveness, retention and performance (Shaju \& Subhashini, 2017). Enhanced levels of performance have a positive impact of job satisfaction. This can be grounded from the social exchange theory (Cropanzano \& Mitchell, 2005), which provides an avenue of explanation in that it presents that social behaviour is the result of an exchange process with the intention to maximise benefits and minimise costs. Therefore, if employees feel more satisfied with their job environment and leadership, they will be more inclined to perform better at work, resulting in an enhanced level of job performance, positive work values, high levels of employee motivation, and lower rates of absenteeism, turnover and burnout (Shaju \& Subhashini, 2017).

\section{Organisational commitment}

Organisational commitment refers to the psychological link between employees and the organisation (Meyer \& Allen, 1991). This link creates a bond that will make it less likely that individual employees will leave the organisation voluntarily. Meyer and Allen (1991) referred to three forms of organisational commitment, namely (1) Affective commitment refers to the emotional attachment that employees feel towards their organisations; (2) Continuance commitment entails employees' decision to remain with their organisation, because they deem the cost of leaving too high; and (3) normative commitment refers to employees' bond with an organisation because of a perceived sense of obligation towards the organisation (Meyer \& Allen, 1991). Mehta and Maheshwari (2013) found a statistically significant negative relationship between toxic leadership and organisational commitment. Schmidt's follow-up study found that toxic leadership does not only affect organisational commitment at the individual level but also at the group level. The impact also indicated a statistically negative relationship (Schmidt, 2014), especially concerning the affective commitment dimension of organisational commitment. Furthermore, Weaver and Yancy (2010) also found that forms of destructive leadership behaviour impact negatively on employees' commitment to the organisation.

\section{Turnover intention}

Tett and Meyer (1993) described turnover intention as a conscious and deliberate wilfulness (i.e. conscious and deliberate determination) to leave the organisation. The results of Schmidt's follow-up study (2014) indicated that toxic leadership significantly predicts employee outcomes such as turnover intention. This finding supports Tepper's study which found that abusive supervision predicts turnover (Tepper, 2007). Rayner and Cooper (1997) found a positive relationship between employees' turnover intention and toxic leadership. This finding is supported by Zangaro, Yager and Proulx (2009) investigating the influence of toxic leadership in the nursing profession, which indicates increased absenteeism and higher turnover rates.

\section{Organisational culture}

Organisations are 'living' entities that reflect their own personalities and sets of values, which is what is known as organisational culture (Van der Post et al., 1997):

Organisational culture refers to a system of shared meaning, the prevailing background fabric of prescriptions and proscriptions 
for behaviour, the system of beliefs and values and the technology and task of the organisation together with the accepted approaches to these. (p. 4)

Organisational culture gives meaning and direction to all employees (Van der Post et al., 1997) by creating the environment within which the organisation functions (Sempane et al., 2002). According to Van der Post et al. (1997), organisational culture can be broken down into 15 different factors (e.g. conflict resolution, culture management, customer orientation, disposition towards change, employee participation, goal clarity, human resource orientation, identification with the organisation, locus of authority, management style, organisation focus, organisation integration, performance orientation, reward orientation and task structure).

Various other studies were conducted on organisational culture (e.g. Appelbaum \& Roy-Girard, 2007; Bass, 1995). These scholars agreed that the survival of an organisation depends on the shaping of its culture by effective leaders. Imran et al. (2012) examined the role of culture as a possible mediator, because of the underlying importance of organisational culture in the overall performance of the organisation. Their results are supported by Rasid et al. (2013), who indicate that culture mediates the relationship between leadership and organisational commitment. According to Appelbaum and Roy-Girard (2007), toxic leaders create a toxic workplace, which over time will impact the organisation's culture - because of the cumulative effect of their actions. The scholars argue that the glue, which keeps this toxicity together, is the culture of the organisation. In other words, the higher up the toxic leaders' position is in the organisation, the stronger their influence would be on the culture (Appelbaum \& Roy-Girard, 2007). Therefore, the inference can be drawn that toxic leaders create a toxic culture by changing the content of the organisation's culture (Giberson et al., 2009). It is, therefore, important that the mediating effect of organisational culture be investigated in the study.

\section{Research design \\ Research approach}

The study followed a quantitative research approach and used a cross-sectional research design. This form of research focusses on gathering numerical data and generalising it across groups of people or explaining a particular phenomenon (Babbie, 2010). The term 'cross-sectional' in a research design refers to the collection of data in more than one case, and at a single point in time. For this study, the advantage was that the data could be collected at a single point in time and from a specific population in the manufacturing sector (Struwig \& Stead, 2013).

\section{Research method}

\section{Research participants}

This study used a combined convenience and purposive nonprobability sample (Coolican, 2014; De Vos et al., 2011), consisting of 600 respondents representative of the population in the steel and paper manufacturing industry to complete the questionnaires. Inclusion criteria used were: (1) wellversed in English; (2) between the ages of 18 and 65 years; and (3) defined as full-time working adults. The data are reflected in Table 1.

The data in Table 1 indicate that the majority of the respondents (58.9\%) were in the age group of 35-65 years, whilst $40.4 \%$ was under the age of 35 years. The gender characteristics of the respondents indicate that most of them were males $(79.9 \%)$, with only $20.1 \%$ females. The majority of the respondents were African (58.6\%), followed by White $(22.3 \%)$, Indian $(12.5 \%)$, people of mixed race $(6.3 \%)$ and others $(0.2 \%)$. Most of the respondents spoke isiZulu (52.6\%), followed by English (35.1\%), Afrikaans $(11 \%)$, isiXhosa $(0.8 \%)$ and Sesotho $(0.3 \%)$. In terms of education, most of the respondents had a Grade 12/Matric certificate $(58.4 \%)$, followed by a diploma (21.5\%), degree $(11.3 \%)$, postgraduate qualification $(2.7 \%)$ and others $(5.8 \%)$. Based on the occupational level, the data indicate that most of the respondents were employed at the skilled technical level $(45.4 \%)$, followed by semi-skilled (28.6\%), unskilled $(13.8 \%)$, middle management $(8.2 \%)$ and senior management $(2.8 \%)$.

\begin{tabular}{|c|c|c|}
\hline Item & Frequency & Percentage \\
\hline \multicolumn{3}{|l|}{ Age } \\
\hline 1951-1981 & 354 & 58.9 \\
\hline 1982-1998 & 243 & 40.4 \\
\hline \multicolumn{3}{|l|}{ Gender } \\
\hline Male & 480 & 79.9 \\
\hline Female & 120 & 20.1 \\
\hline \multicolumn{3}{|l|}{ Race } \\
\hline African people & 352 & 58.6 \\
\hline People of mixed race & 38 & 6.3 \\
\hline Indian people & 75 & 12.5 \\
\hline White people & 134 & 22.3 \\
\hline Other & 1 & 0.2 \\
\hline \multicolumn{3}{|l|}{ Language } \\
\hline Afrikaans & 66 & 11.0 \\
\hline English & 211 & 35.1 \\
\hline isizulu & 316 & 52.6 \\
\hline Sesotho & 2 & 0.3 \\
\hline isiXhosa & 5 & 0.8 \\
\hline \multicolumn{3}{|l|}{ Educational level } \\
\hline Grade 12/Matric & 351 & 58.4 \\
\hline Diploma & 129 & 21.5 \\
\hline Degree & 68 & 11.3 \\
\hline Postgraduate & 16 & 2.7 \\
\hline Other & 35 & 5.8 \\
\hline Occupational level & 17 & 2.8 \\
\hline \multicolumn{3}{|l|}{ Senior management } \\
\hline $\begin{array}{l}\text { Professionally qualified and experienced } \\
\text { specialists and mid-management }\end{array}$ & 49 & 8.2 \\
\hline $\begin{array}{l}\text { Skilled technical and academically qualified } \\
\text { workers, junior management, supervisors, } \\
\text { foreman and superintendents }\end{array}$ & 273 & 45.4 \\
\hline Semi-skilled and discretionary decision-making & 172 & 28.6 \\
\hline Unskilled and defined decision-making & 83 & 13.8 \\
\hline
\end{tabular}




\section{Measuring instruments}

Demographical characteristics (such as gender, age, language, highest qualification achieved and occupational level) of the participants were gathered using a biographical questionnaire. These characteristics were only included to describe the data.

Toxic Leadership Scale: Toxic leadership was measured by the scale developed by Schmidt in 2008. The 30-item scale measures five dimensions, namely, abusive supervision (seven items), for example: 'My supervisor speaks poorly about subordinates to other people in the workplace'; authoritarian leadership (six items), for example: 'My current supervisor determines all decisions in the unit whether they are important or not'; narcissism (five items), for example: 'My current supervisor thrives on compliments and personal accolades'; self-promotion (five items), for example: 'My current supervisor denies responsibility for mistakes made in his/her unit'; and unpredictability (seven items), for example: 'My current supervisor has explosive outbursts'.

The above-mentioned dimensions were scored on a 5-point Likert-type scale, ranging from 1 (strongly disagree) to 5 (strongly agree). The reliability of the scale using Cronbach's alpha coefficients was calculated at 0.93 for abusive supervision, 0.89 for authoritarian leadership, 0.88 for narcissism, 0.91 for self-promotion and 0.92 for unpredictability. The overall Cronbach's alpha score was 0.90, suggesting that the instrument is reliable (Schmidt, 2008).

Minnesota Satisfaction Questionnaire: This instrument meant to measure job satisfaction was adapted by Buitendach and Rothmann (2009) for use in the South African context. The questionnaire requires respondents to rate the experience of their jobs based on extrinsic and intrinsic factors for job satisfaction. This questionnaire consists of 17 items: eight that measure extrinsic job satisfaction, and nine that measure intrinsic job satisfaction. Example item for extrinsic job satisfaction is: 'The way my boss handles his/ her workers'; and for job satisfaction is: 'The way my job provides for steady employment'. The scale was measured on a 5-point Likert-type scale, ranging from very satisfied to very dissatisfied. Buitendach and Rothmann (2009) found the scale to be reliable and valid, with a Cronbach's alpha coefficient of 0.86 .

Turnover Intention Scale: This six-item scale (TIS-6), which was adapted from the 15-item scale developed originally by Roodt (2004), was used to measure turnover intention. This scale was validated for use in South Africa by Bothma and Roodt (2013); it was found to be reliable with a Cronbach's alpha coefficient of 0.80 , and was therefore used to assess turnover intention (Bothma \& Roodt, 2013). An example item is: 'How often have you considered leaving your job?' The TIS-6 was scored on a 5-point scale, ranging from a score of 1 (never) to 5 (always).
Organisational Commitment Scale: This 24-item scale of Meyer and Allen (1991) was used to measure organisational commitment. This scale measures three dimensions of organisational commitment: continuance, affective and normative commitments.The Organisational Commitment Scale (OCS) was scored on a 5-point Likert-type scale, ranging from a score of 1 (strongly disagree) to 5 (strongly agree). The reliability and validity for use of the OCS within the South African context were confirmed by studies from Coetzee, Schreuder and Tladinyane (2007), Ferreira (2009), as well as Lumley (2010). The Cronbach's alpha coefficients for these dimensions in the above-mentioned studies ranged between 0.70 and 0.83 , which indicates a high reliability for the scale.

Organisational culture questionnaire: This instrument, developed by Van der Post et al. (1997), was used to measure organisational culture. The questionnaire has a total of 97 items, which cover 15 factors that were considered in this study to measure organisational culture. The organisational culture questionnaire (OCQ) was scored on a 7-point Likerttype scale, ranging from 1 (strongly disagree) to 7 (strongly agree). The Cronbach's alpha coefficients for the different factors range between 0.79 and 0.93 (Van der Post et al., 1997). The overall reliability of the scale is 0.99 (Erwee et al., 2001).

\section{Research procedure and ethical considerations}

The Human Resource Managers of the various companies acted only as gatekeepers, ensuring access to the participants to ensure data collection. In total, 800 questionnaires were distributed to the various organisations, and 600 were collected. Data collection was done in the manufacturing sector and in the work environment, which is familiar to the researcher, using a questionnaire booklet that was individually administered. Accompanying the questionnaire booklets was a letter of introduction and an explanation of the objectives and importance of the study. Participants were accommodated in the training centre or empty office space of the organisations to complete the questionnaires.

Although this was a self-administrated questionnaire, a field worker working as a human resource intern was available at one of the organisations to assist participants who found it difficult to complete the questionnaire because of low literacy levels. The fieldworker was trained to assist the participants during the data collection phase. No personal information was recorded on the booklet, to ensure anonymity, respect privacy and ensure confidentiality (De Vos et al., 2011). Furthermore, no ethical guidelines were breached by the researcher during the process. The researcher maintained the respect and dignity of the participants throughout and adhered to the ethical considerations (De Vos et al., 2011). Sufficient time was allocated for the participants to complete the survey.

The researcher coordinated the distribution of the questionnaires, as well as the collection and safe storing of completed booklets. After all the booklets were collected, the data were captured and the statistical analysis commenced. 


\section{Statistical analysis}

Statistical analysis was carried out using the SSPS program version 25 (IBM SPSS Inc., 2017) and AMOS 20 (Arbuckle, 2011). Data were analysed through descriptive and inferential statistics such as means, standard deviation, skewness and kurtosis. The Cronbach's alpha coefficients were calculated to determine reliability, with values of 0.70 , which according to Pallant (2010), can be regarded as reliable. Confirmatory factor analysis (CFA) was done on the different scales of toxic leadership, turnover intention, organisational commitment, job satisfaction and organisational culture. The results for all scales indicated that they could be used in their present form to complete the statistical analysis.

To determine the relationships between variables (i.e. toxic leadership, job satisfaction, organisational commitment and turnover intention) and the strength of these relationships, product-moment correlations and Pearson's correlation coefficient were used. The correlation coefficient cut-off scores were set at -1 to +1 , with -1 indicating a negative relationship, 0 no relationship and +1 a positive relationship. Statistical significance was set at $95 \%(p \leq 0.05)$. Practical significance was determined using effect size, and its cut-off point was set at 0.30 for medium effect and 0.50 for large effect (Steyn \& Swanepoel, 2008).

The aim was to test whether organisational culture has a mediational effect between toxic leadership and certain job outcomes such as job satisfaction, commitment and turnover intention. For this test, structural equation modelling (SEM) was used as implemented by AMOS (Arbuckle, 2011). Several goodness-of-fit indices were used, namely, chi-square $\left(\chi^{2}\right)$, the Comparative Fit Index (CFI), Tucker-Lewis Index (TLI) and the root mean square error of approximation (RMSEA). Acceptable goodness-of-fit indices had the following cut-off points: non-significant $\chi^{2}$ values; CFI and TLI values larger than or equal to 0.90; and RMSEA values smaller than or equal to 0.08 (Byrne, 2010).

\section{Results}

It is evident from the results that most variables were found to be distributed normally. The measuring instruments also showed acceptable levels of internal consistency. Furthermore, the results also indicate Cronbach's alpha coefficients with acceptable levels of reliability. These coefficients range between 0.66 and 0.85 . All the Cronbach's alpha values were found to be above the cut-off point of $\alpha>0.70$, except for normative commitment, cultural management, performance orientation and task structure, but these are still regarded as reliable (Pacleb \& Cabanda, 2014; Pallant, 2010; Pevalin \& Robson, 2009).

\section{Correlations}

The correlation coefficients between the constructs are presented in Table 2.

\section{Toxic leadership and job satisfaction}

Considering the relationship between toxic leadership dimensions and job satisfaction, it is evident from Table 2 that abusive supervision and authoritarian leadership are positively, statistically and practically (with a medium effect) related to intrinsic job satisfaction. Narcissism, self-promotion and unpredictability, and toxic leadership dimensions were statistically and practically related to a small effect on intrinsic job satisfaction. Furthermore, abusive supervision, authoritarian leadership, self-promotion and unpredictability were positively, statistically and practically (with a medium effect) related to extrinsic job satisfaction. Only narcissism as a toxic leadership dimension was shown to be positively related to a small effect on extrinsic job satisfaction.

\section{Toxic leadership and turnover intention}

The relationship between toxic leadership dimensions and turnover intention indicates (Table 2) that all the toxic leadership dimensions are positively, statistically and practically (with a medium effect) related to turnover intention.

\section{Toxic leadership and commitment}

Regarding the relationship between toxic leadership dimensions and commitment, it was found that the toxic leadership factors all have statistically a significant negative relationship with affective commitment. The four factors abusive supervision, authoritarian leadership, self-promotion and unpredictability - were all practically significant

TABLE 2: Correlation matrix between constructs.

\begin{tabular}{|c|c|c|c|c|c|c|c|c|c|c|c|}
\hline Variable & 1 & 2 & 3 & 4 & 5 & 6 & 7 & 8 & 9 & 10 & 11 \\
\hline 1. Abusive & 1 & - & - & - & - & - & - & - & - & - & - \\
\hline 2. Authoritarian & $0.73 * * t$ & 1 & - & - & - & - & - & - & - & - & - \\
\hline 3. Narcissism & $0.63 * *+$ & $0.65 * *$ & 1 & - & - & - & - & - & - & - & - \\
\hline 4. Self-promotion & $0.73 * *$ & $0.71 * * *$ & $0.69 * * \dagger$ & 1 & - & - & - & - & - & - & - \\
\hline 5. Unpredictable & $0.73 * *+$ & $0.66 * *$ & $0.61 * * \dagger$ & $0.74 * * \vdots$ & 1 & - & - & - & - & - & - \\
\hline 6. Intrinsic job satisfaction & $0.32 * * \dagger$ & $0.32 * * \dagger$ & $0.13 * *$ & $0.22 * *$ & $0.24 * *$ & 1 & - & - & - & - & - \\
\hline 8. Affective commitment & $-0.37 * * \dagger$ & $-0.32 * *$ & $-0.29 * *$ & $-0.38 * t$ & $-0.38 * * \dagger$ & $-0.42 * * \dagger$ & $0.51 * *+$ & 1 & - & - & - \\
\hline 9. Continuance commitment & -0.01 & $0.08 *$ & 0.06 & 0.07 & $0.09 *$ & -0.06 & -0.00 & $0.14 * *$ & 1 & - & - \\
\hline 10. Normative commitment & $-0.10^{*}$ & $-0.09 *$ & $-0.12 * *$ & $-0.09 *$ & -0.07 & $-0.22 * *$ & $-0.24 * *$ & $0.46 * * \dagger$ & $0.26 * *$ & 1 & - \\
\hline 11. Turnover intention & $0.39 * * \dagger$ & $0.34 * * \dagger$ & $0.33 * * \dagger$ & $0.38 * * \dagger$ & $0.38 * * \dagger$ & $0.35 * * \dagger$ & $0.53 * * t$ & $-0.64 * * \dagger$ & $-0.10 * *$ & $-0.40 * * \dagger$ & 1 \\
\hline
\end{tabular}

$*, p<0.05$ for all values; $* *, p<0.01$ for all values.

$\dagger$, Correlation $\geq 0.30$ is practically significant (medium effect); $\$$, Correlation $>0.50$ is practically significant (large effect). 
with medium effect. Authoritarian and unpredictable leadership were statistically significantly positively related to continuance commitment; however, this relationship was found to be only to a small extent. Furthermore, abusive supervision, authoritarian leadership, narcissism and selfpromotion were negatively, statistically and practically (with a very small effect) related to normative commitment.

\section{Mediation analysis}

The results of the mediation analysis are discussed and displayed in Figure 1.

Structural equation modelling was used to test the proposed mediating effect of organisational culture between toxic leadership and job satisfaction, organisational commitment and turnover intention. The hypothesised mediation model above tested whether organisational culture mediates the relationship between toxic leadership and job outcomes, namely, turnover intention, job satisfaction and organisational culture. The results indicated a significant negative relationship between toxic leadership and organisational culture $\left(R^{2}=-0.50 ;\right.$ SE $\left.0.05 ; p=0.00\right)$. Furthermore, a significant negative relationship was found between organisational culture and job satisfaction $\left(R^{2}=-0.48\right.$; SE $0.02, p=0.00)$. The results indicated a significant positive relationship between organisational culture and organisational commitment $\left(R^{2}=0.56\right.$; SE $\left.0.04, p=0.00\right)$, and a significant negative relationship between organisational culture and turnover intention $\left(R^{2}=-0.51\right.$; SE $\left.0.05, p=0.00\right)$.

The overall model was tested in three separate models, the results of which are displayed below. The mediation was partial for all the models that were tested and explain $45.8 \%$ of the variance in job satisfaction, $63.5 \%$ of the variation in organisational commitment and $71.6 \%$ of the variance in turnover intention.

Table 3 displays the goodness-of-fit statistics for the three models.

Marsh, Hau and Wen (2004) cautioned that an acceptable model can be rejected if there is a strict adherence to cut-off values. Marsh et al. referred to a traditional cut-off values amounting to "little more than rules of thumb based largely on intuition and have little theoretical justification" (2004, p. 321). Cut-off points should only be considered as guidelines, as there is little consensus on the values for

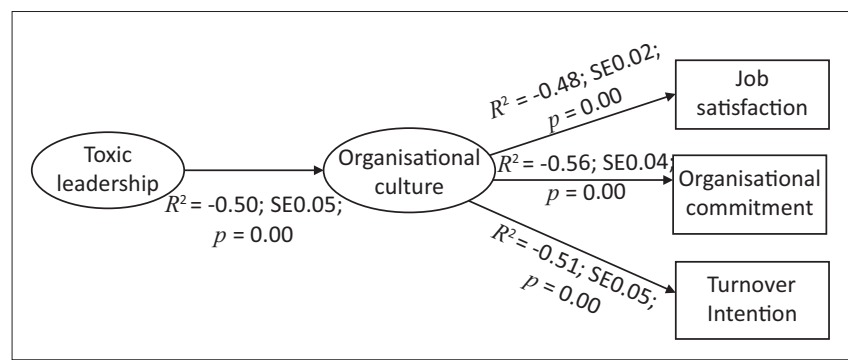

FIGURE 1: Organisational culture mediation across the models. adequate fit (Lance, Butts, \& Michels, 2006). According to Hooper, Coughlan and Mullen (2008), researchers must not lose sight of the substantive theory. In other words, by allowing model fit to drive the research, it moves the research away from the original theory-testing purpose.

As mentioned above, the overall model was tested in three separate models and is described below.

Model 1 tested the proposed mediating effect of organisational culture between toxic leadership and job satisfaction. The hypothesised models all provided an adequate fit to the data. The CFI value for Model 1 was found to be at 0.90 , the TLI (0.88) value just below the cut-off point of 0.90 and RMSEA was 0.09 , which is indicative of a fit that is neither good nor bad. Model 1, therefore, shows acceptable model fit.

Model 2 tested the proposed mediating effect of organisational culture between toxic leadership and commitment. In terms of Model 2, both the CFI (0.89) and TLI (0.87) values were found to be just below the cut-off point, but RMSEA was 0.09, which is indicative of a fit that is neither good nor bad. Model 2 shows weak but acceptable fit.

Model 3 tested the proposed mediating effect of organisational culture between toxic leadership and turnover intention. Model 3 has TLI (0.86) and CFI (0.88) just below the acceptable cut-off point. Root mean square error of approximation was 0.09 , which indicates a fit that is neither good nor bad. Therefore, Model 3 shows weak but acceptable fit.

Table 4 displays the results of the mediating effects of organisational culture. The mediation model tested whether organisational culture mediates the relationship between toxic leadership, job satisfaction, organisational commitment and turnover intention. The model does not specify whether the mediation is full or partial. The test results returned both direct and indirect effects for all the relationships tested, which indicated that mediation is only partial in all of the relationships. In terms of job satisfaction, results indicated that organisational culture does mediate the relationship between toxic leadership and job satisfaction. This mediation is found to be partial and explained $45.8 \%$ of the variance in job satisfaction. In addition, organisational culture also mediates the relationship between toxic leadership and organisational commitment. This mediation is partial and explains $63.5 \%$ of the variation in organisational commitment. In terms of the results, it confirmed that organisational culture does mediate the relationship between toxic leadership and turnover intention. This mediation was found to be partial and explains $71.6 \%$ of the variance in turnover intention.

TABLE 3: Goodness-of-fit statistics for all three models.

\begin{tabular}{lcccccc}
\hline Models & $\chi^{2}$ & $\chi^{2} / \mathrm{df}$ & TLI & CFI & RMSEA & $\boldsymbol{p}$ \\
\hline Model 1 (Job satisfaction) & 1178.69 & 6.34 & 0.88 & 0.90 & 0.09 & 0.00 \\
Model 2 (Commitment) & 1288.55 & 6.26 & 0.87 & 0.89 & 0.09 & 0.00 \\
Model 3 (Turnover intention) & 1514.89 & 5.57 & 0.86 & 0.88 & 0.09 & 0.00 \\
\hline
\end{tabular}

CFI, Comparative Fit Index; TLI, Tucker-Lewis Index; RMSEA, root mean square error of approximation. 
TABLE 4: Mediating effects of organisational culture (standardised effects).

\begin{tabular}{|c|c|c|c|c|c|c|c|c|c|}
\hline \multirow[t]{2}{*}{ Predictors } & \multicolumn{3}{|c|}{ Job satisfaction $(45.8 \%)$} & \multicolumn{3}{|c|}{ Commitment $(63.5 \%)$} & \multicolumn{3}{|c|}{ Turnover intention $(71.6 \%)$} \\
\hline & Direct & Indirect & Total & Direct & Indirect & Total & Direct & Indirect & Total \\
\hline Organisational culture & 0.00 & 0.00 & 0.00 & 0.56 & 0.00 & 0.56 & 0.00 & 0.00 & -0.51 \\
\hline Toxic leadership & 0.28 & 0.24 & 0.52 & -0.16 & -0.28 & -0.44 & 0.24 & 0.25 & 0.49 \\
\hline
\end{tabular}

\section{Discussion}

The first objective of this study was to investigate whether there is a relationship between toxic leadership, job satisfaction, turnover intention and organisational commitment among employees within the manufacturing industry. In this study, job satisfaction was divided into extrinsic and intrinsic forms. This study theorised that there will be a statistically significant negative relationship between toxic leadership and job satisfaction. This postulate is in line with other studies by Mehta and Maheshwari (2013), Kusy and Holloway (2009), as well as Schmidt (2014). The results did indicate a statistically significant relationship. However, in this study, the relationship was found to be positive for extrinsic job satisfaction, which implies that the more toxic the leader, the more satisfied the employees seemed to be. The finding above was the case, especially for authoritarian leadership, abusive supervision factors and extrinsic job factors. These job factors deal with aspects such as company policies, working conditions, remuneration and the way the employees get along. It is suggested that such a result could be because of the makeup of the study population. A significant number of participants are unskilled and semiskilled workers (42.4\%), and at this level, they are also given constant guidance on how to complete tasks. Such constant supervision and guidance may contribute to the perception that they feel secure in their performance. This could be the reason for the positive experience of job satisfaction.

The relationship between toxic leadership dimensions and turnover intention indicates that all the toxic leadership dimensions are positively, statistically and practically significant (with a medium effect) in relation to turnover intention. The more the leader is viewed as toxic, the stronger the potential for turnover. The results are also in line with those of Schmidt $(2008,2014)$ and Akca $(2017)$, who found a statistically significant positive relationship between toxic leadership and turnover intention. In the manufacturing industry, which is labour-intensive, high turnover rates have a direct impact on productivity, because the new employee may not be as productive as the one who has just left, at least initially. According to Sarmiento et al. (2006), employee turnover can potentially cost a company indirectly through failed implementation of continuous improvement practices, and directly through mistakes that untrained, unskilled new employees might cause.

This study theorised a statistically significant negative relationship between toxic leadership and organisational commitment, similar to the finding of Mehta and Maheshwari (2013). As expected, it was found that toxic leadership factors all have statistically significant negative relationships with affective commitment. The current results indicate that the most significant impact of toxic leadership is made on the employees' feelings towards their organisation - or affective commitment. Lower levels of commitment in a manufacturing organisation will lead to absenteeism and decrease the production volumes because of staff shortages. This in turn will impact the organisation's financial situation negatively if absenteeism continues unabated (Weaver \& Yancy, 2010).

The second objective of this study was to determine whether organisational culture mediates the relationship between toxic leadership and certain job outcomes (e.g. job satisfaction, turnover intention and organisational commitment) among employees within the manufacturing industry. Direct and indirect effects were returned for all the relationships tested, which indicates that mediation was found to be only partial in all of the relationships. Organisational culture explains $45.8 \%$ of the variance in the relationship between toxic leadership and job satisfaction; it further explains $63.5 \%$ of the variation in the relationship between toxic leadership and organisational commitment. In terms of turnover intention, organisational culture explains $71.6 \%$ of the variance in the relationship between toxic leadership and turnover intention. The partial mediation in all the tested relationships indicates that when employees experience a leader to be toxic, it can have a negative influence on the organisation's culture. Such a toxic organisational culture may in turn cause employees, who are less committed and feel dissatisfied with their workplace, wanting to leave the organisation. These results confirm findings from previous studies that organisational culture functions as a mediator (e.g. Imran et al., 2012; Rasid et al., 2013; Schmidt, 2014).

\section{Practical implications}

According to Mehta and Maheshwari (2014), the behaviour and performance of leaders must be monitored and assessed constantly to ensure their interactions with staff are conducive to healthy work environments. Organisations often lack the experience and abilities to counteract the effects of toxic leadership, thus usually being forced to pay the hidden costs inflicted by the dysfunctional behaviour of the toxic leader. These hidden costs may entail: reduced productivity because of an increase in absenteeism and sick leaves; weak performance of employees caused by commitment and dissatisfaction at work; decreased brand equity as a result of reputational damages of the organisation and legal costs (Vreja, Balan, \& Bosca, 2016). It is anticipated that studies such as these will encourage the organisations to focus more on instances of toxic leadership within and help them put checks and balances in place to ensure the early detection of toxic leaders (Mehta \& Maheshwari, 2014). In this regard, this study will help initiate interventions, where management within organisations can focus on dealing with identified toxic leaders. 
Leadership studies have indicated that employees tend to blame the organisation as a whole for having a culture that tolerates toxic leadership. Employees respond to this perceived culture of tolerance by being negatively inclined towards the organisation as a whole (Folger \& Cropanzano, 2001). This study has indicated that such a negative response among employees is true to an extent. It has provided empirical data to support the statement that toxic leadership has a significant impact on job outcomes, and in turn on employees having to cope with such an organisational culture.

The focus of the research, being a novel topic in the South African context, has expanded on the knowledge of toxic leadership. In this regard, this study as such has increased the opportunity to deal effectively with the destructive impact of toxic leadership on employees and organisations at large.

A practical implication for employees in the manufacturing industry is that this study provides them with an explanation of toxic leadership as a leadership style, and how it is intertwined with an organisation's culture. The results explain further as to how this leadership style may affect employees in the workplace: an insight which could help them make crucial decisions about their jobs and future career. This study provides human resource professionals an in-depth understanding of the phenomenon of toxic leadership. This focus may be a starting point to help organisations decrease the prevalence of toxic leadership styles, thereby reducing its destructive impact within the workplace.

\section{Limitations and recommendations}

Firstly, the study was confined to the manufacturing sector in South Africa. As indicated, such a restriction of the study population and the sampling procedure may influence the generalisability of the results. Future research should, therefore, replicate the study in different sectors that represent different populations. Such a broadened research scope would provide a true reflection of toxic leadership in South Africa and indicate whether the results in the various sectors are similar or differ considerably.

Secondly, whilst self-promotion had the strongest impact on job outcomes, certain other dimensions showed an amount of impact as well. Thus, it would be advantageous to organisations if research could investigate the variance that is unique to all five dimensions of toxic leadership.

Thirdly, this study confirmed relationships as well as predictors in a small section of the manufacturing industry. Therefore, it would be valuable to continue these studies in other manufacturing organisations to generate more generalised results. Such a focus applies especially to this study's unique finding on the positive experience of job satisfaction. This finding is not in line with other studies; therefore, future research should replicate the study to assess whether this result is specific to this study population only.
In addition, the study should be expanded into other sectors to confirm the relationships between toxic leadership and job outcomes, predictors and organisational culture as a mediator. Such future research would be valuable, especially in light of the fact that currently there are no other studies in South Africa with which results can be compared. It would also be recommended that this study should compare if the same results occur in various occupation levels from the same population.

Finally, although the mediation results indicated directional relationships between toxic leadership and job outcomes, the data were not collected over an extended period of time; consequently, it was not possible to test the assumptions empirically. Therefore, the use of longitudinal studies can assist by measuring directional relationships over an extended period of time. Such an approach will deliver richer data and have positive implications for operational interventions, because it may give a deeper insight to the cause and effect aspects (De Vos et al., 2011).

\section{Conclusion}

This study provided the first analysis of toxic leadership within a South African working environment. The findings indicated the impact of this leadership style on certain job outcomes such as turnover intention, job satisfaction and organisational commitment. The study also investigated the mediation role of organisational culture. It is important that other researchers build on the abovementioned recommendations for future studies, because several questions remain unanswered, for example, the unexpected difference in the result of job satisfaction.

\section{Acknowledgements}

The authors convey their appreciation to Prof. Suria Ellis for the statistical analysis, and Ds. Claude Vosloo for the language editing of the dissertation. Furthermore, credit goes to Dr Marissa Brouwers as supervisor of the dissertation.

\section{Competing interests}

The authors declare that they have no financial or personal relationships that may have inappropriately influenced them in writing this article.

\section{Authors' contributions}

A.P. fulfilled the role of the primary researcher, and this study formed part of her master's research dissertation. She was responsible for the conceptualisation of the article, collection of the data, interpretation of the research results and the writing of the article. M.B. acted as supervisor and played an advisory role in this study and assisted with the conceptualisation of the study design, the describing of statistical procedures and reporting, and assisted in the writing of the research article. 


\section{Funding information}

This study was supported by the North-West University (publishing of the article).

\section{Data availability statement}

Data sharing is not applicable to this article as no new data were analysed or created in this study.

\section{Disclaimer}

The views and opinions expressed in this article are those of the authors and do not necessarily reflect the official policy or position of any affiliated agency of the authors.

\section{References}

Akca, M. (2017). The impact of toxic leadership on intention to leave of employees. International Journal of Economics, Business \& Management Research, 1(4), Internation 288 .

Appelbaum, S.H., \& Roy-Girard, D. (2007). Toxins in the workplace: Affect on organizations and employees. Corporate Governance: The international Journal of Business in Society, 7(1), 17-28. https://doi.org/10.1108/14720700710727087

Arbuckle, J.L. (2011). IBM SPSS Amos 20.0. User's guide, Mount Pleasant, SC: Amos Development Corporation.

Ashforth, B.E. (1997). Petty tyranny in organizations: A preliminary examination of antecedents and consequences. Canadian Journal of Administrative Sciences/ Revue Canadienne des Sciences de l'Administration, 14(2), 126-140. https://doi. org/10.1111/j.1936-4490.1997.tb00124.x

Babbie, E.R. (2010). The practice of social research. Belmont, CA: Wadsworth Cengage.

Bass, B.M. (1995). Leadership and performance beyond expectation. New York, NY: The Free Press.

Bothma, C.F.C., \& Roodt, G. (2013). The validation of the turnover intention scale South African Journal of Human Resources Management, 11(1), 1-12. https://doi. org/10.4102/sajhrm.v11i1.507

Buitendach, J.H., \& Rothmann, S. (2009). The validation of the Minnesota Job Satisfaction questionnaire in selected organisations in South Africa. South African
Journal of Human Resource Management, $7(1), 1-8$. https://doi.org/10.4102/ sournal of Hum

Byrne, B.M. (2010). Structural equation modelling with AMOS: Basic concepts, applications and programming (2nd edn.). Mahwah, NJ: Lawrence Erlbaum.

Coetzee, M., Schreuder, A.M.G., \& Tladinyane, R. (2007). Organisational commitment and its relation to career anchors. Southern African Business Review, 11(1), 65-86.

Coolican, H. (2014). Research methods and statistics in psychology (6th ed.). New York, NY: Psychology Press.

Cropanzano, R., \& Mitchell, M.S. (2005). Social exchange theory: An interdisciplinary review. Journal of Management, 31(6), 874-900. https://doi.org/10.1177/ 0149206305279602

De Vos, A.S., Strydom, H., Fouché, C.B., \& Delport, C.S.L. (2011). Research at grassroots: For the social sciences and human service professions (4th edn.). grassroots: For the
Pretoria: Van Schaik.

Dladla, J.T. (2011). The influence of leader behaviour, psychological empowerment, job satisfaction, and organizational commitment on turnover intention (Unpublished master's dissertation). University of Stellenbosch, Stellenbosch.

Dobbs, J.M. (2014). The relationship between perceived toxic leadership styles, leade effectiveness, and organizational cynicism (Unpublished doctoral thesis). University of San Diego, San Diego, CA.

Du Toit, M. (2015). The influence of leader integrity on ethical leadership, interactional justice, leader trust and counterproductive work behaviour (Unpublished master's dissertation). University of Stellenbosch, Stellenbosch.

Ebrahim, Z., \& Pieterse, J.J. (2016). A strategy to tailor performance interventions based on the nature of organisational maturity of South manufacturing firms. The
South African Journal of Industrial Engineering, 27(2), 81-94. https://doi.org/ South African Journal
$10.7166 / 27-2-1328$

Erwee, R., Lynch, B., Millett, B., Smith, D., \& Roodt, G. (2001). Cross-cultural equivalence of the organisational culture survey in Australia. Journal of Industrial Psychology, 27, 7-12.

Ferreira, N. (2009). The relationship between psychological career resources and organisational commitment (Unpublished master's dissertation). University of Pretoria, Pretoria.

Folger, R., \& Cropanzano, R. (2001). Fairness theory: Justice as accountability. Advances in Organizational Justice, 1, 1-55.

Giberson, T.R., Resick, C.J., Dickson, M.W., Mitchelson, J.K., Randall, K.R., \& Clark, M.A. (2009). Leadership and organizational culture: Linking CEO characteristics to cultural values. Journal of Business \& Psychology, 24(2), 123-137. https://doi. org/10.1007/s10869-009-9109-1
Heine, G. (2013). The influence of integrity and ethical leadership on trust and employee work engagement (Unpublished master's dissertation). University of Stellenbosch, Stellenbosch.

Hooper, D., Coughlan, J., \& Mullen, M. (2008). Structural equation modelling: Guidelines for determining model fit. Electronic Journal of Business Research Methods, 6(1), 53-60.

IBM Corp. (2017). IBM SPSS statistics for windows, Version 25.0. Armonk, NY: IBM Corp.

IDC (Industrial Development Corporation). (2019). Economic trends: Key trends in the South African economy. Retrieved from http://www.idc.co.za/images/downloadfiles/economicoverviews/RI-publication-Keytrends-in-SA-economy_March2019.pdf

Imran, R., Zahoor, F., \& Zaheer, A. (2012). Leadership and performance relationship: Culture matters. International Journal of Innovation, Management \& Technology, 3(6), 713.

Kusy, M., \& Holloway, E. (2009). Toxic workplace: Managing toxic personalities and their systems of power. San Francisco, CA: Jossey-Bass.

Lance, C.E., Butts, M.M., \& Michels, L.C. (2006). The sources of four commonly reported cut-off criteria: What did they really say? Organizational Research Methods, 9(2), 202-220. https://doi.org/10.1177\%2F1094428105284919

Leet, E. (2011). The impact toxic or severe dysfunctional leadership has on the effectiveness of an organisation (Doctoral dissertation). Murdoch University.

Lazarczyk, L. (2017). Life meets work survey finds $56 \%$ of employees have a toxic leader. Retrieved from https://www.prnewswire.com/news-releases/life-meetswork-survey-finds-56-of-employees-have-a-toxic-leader-300473884.html

Lipman-Blumen, J. (2005). The allure of toxic leaders: Why we follow destructive bosses and corrupt politicians - And how we can survive them. Oxford: Oxford University Press.

Lok, P., \& Crawford, J. (2003). The effect of organisational culture and leadership style on job satisfaction and organisational commitment: A cross national comparison. Journal of Management Development, 23(4), 321-328. https://doi.org/10. 1108/02621710410529785

Lumley, E. (2010). Exploring the relationship between career anchors, job satisfaction and organisational commitment (Unpublished master's dissertation). University of South Africa, Pretoria.

Marsh, H.W., Hau, K.T., \& Wen, Z. (2004). In search of golden rules: Comment on hypothesis-testing approaches to setting cut off values for fit indexes and dangers in overgeneralizing $\mathrm{Hu}$ and Bentler's (1999) findings. Structural Equation Modeling, 11(3), 320-341. https://doi.org/10.1207/s15328007sem1103_2

Mehta, S., \& Maheshwari, G.C. (2013). Consequence of toxic leadership on employee job satisfaction and organizational commitment. Journal of Contemporary Management Research, 8(2), 1-23.

Mehta, S., \& Maheshwari, G.C. (2014). Toxic leadership: Tracing the destructive trail. International Journal of Management, 5(10), 18-24.

Meyer, J.P., \& Allen, N.J. (1991). A three-component conceptualisation of organisational commitment. Human Resource Management Review, 1(1), 61-89. https://doi.org/10.1016/1053-4822(91)90011-Z

Pacleb, T.G., \& Cabanda, E. (2014, June). Examining the role of leadership styles and leader communication styles on leader-member exchange relationship and conflict management among bank employees in the Philippines. Paper presented at the Asian Conference on the Social Sciences, Osaka.

Padilla, A., Hogan, R., \& Kaiser, R.B. (2007). The toxic triangle: Destructive leaders, susceptible followers, and conducive environments. The Leadership Quarterly, 18(3), 176-194. https://doi.org/10.1016/j.leaqua.2007.03.001

Pallant, J. (2010). SPSS survival manual: A step by step guide to data analysis using the SPSS program (4th edn.). New York, NY: McGraw-Hill.

Pevalin, D., \& Robson, K. (2009). The stata survival manual. Berkshire: McGraw-Hill Education.

Rayner, C., \& Cooper, C. (1997). Workplace bullying: Myth or reality can we afford to ignore it? Leadership \& Organization Development Journal, 18(4), 211-214. https://doi.org/10.1108/01437739710182313

Rasid, S.Z.A., Manaf, M.A.A., \& Quoquab, F. (2013). Leadership and organizational commitment in the Islamic banking context: The role of organizational culture as a mediator. American Journal of Economics, 3(5), 171-176. https://doi.org/ 10.5923/c.economics.201301.29

Roodt, G. (2004). Turnover intentions (Unpublished document). Johannesburg: University of Johannesburg.

Sadri, G., \& Lees, B. (2001). Developing corporate culture as a competitive advantage. Journal of Management Development, 20(10), 853-859. https://doi.org/10. Journal of Management

Sarmiento, R., Rich, N., Aryee, G., \& Francis, M. (2006). Employee turnover and its effect on sustainable manufacturing operations. Retrieved from http://www. semanticscholar.org/paper

Schein, E. (2004). Organisational culture and leadership (3rd edn.). San Francisco, CA: Jossey- Bass.

Schmidt, A.A. (2008). Development and validation of the toxic leadership scale. Available from ProQuest Dissertations \& Theses Global. (193655997). Retrieved from http://nwulib.nwu.ac.za/login?url=https://search-proquest-com.nwulib.nwu. ac.za/docview/193655977? ?accountid $=12865$

Schmidt, A.A. (2014). An examination of toxic leadership, job outcomes, and the impact of military deployment. Available from ProQuest Dissertations \& Theses Global (1558874321). Retrieved from http://nwulib.nwu.ac.za/login?url=https:// search-proquest-com.nwulib.nwu.ac.za/docview/1558874321?accountid=12865

Schneider, B., Goldstiein, H.W., \& Smith, D.B. (1995). The ASA framework: An update Personnel Psychology, 48(4), 747-773. https://doi.org/10.1111/j.1744-6570.1995. tb01780.x 
Sempane, M.E., Rieger, H.S., \& Roodt, G. (2002). Job satisfaction in relation to organisational culture. South African Journal of Industrial Psychology, 28(2) 23-30. https://doi.org/10.4102/sajip.v28i2.49

Shaju, M., \& Subhashini, D. (2017). A study on the impact of job satisfaction on job performance of employees working in automobile industry, Punjab, India. Journa of Management Research, 9(1), 117-130. https://doi.org/10.5296/jmr.v9i1.10420

Steyn, H.S., \& Swanepoel, C.J. (2008). Praktiese statistiek (2de uitg.). Potchefstroom: Noord-Wes Universiteit.

Struwig, F.W., \& Stead G.B. (2013). Research: Planning, designing and reporting (2nd edn.). Cape Town: Pearson.

Tate, B.W. (2009). Bad to the bone: Empirically defining and measuring negative leadership. Available from ProQuest Dissertations \& Theses Global. (304989652) Retrieved from http://nwulib.nwu.ac.za/login?url=https://search-proquest-com. nwulib.nwu.ac.za/docview/304989652?accountid $=12865$

Tavanti, M. (2011). Managing toxic leaders: Dysfunctional patterns in organizational leadership and how to deal with them. Human Resource Management, 6 , 127-136.

Tepper, B.J. (2007). Abusive supervision in work organisations: Review, synthesis and research agenda. Journal of Management, 33(3), 261-289. https://doi. org/10.1177\%2F0149206307300812
Tett, R.P., \& Meyer, J.P. (1993). Job satisfaction, organisational commitment, turnover intention and turnover: Path analyses based on meta-analytic findings. Personnel Psychology, 46(2), 259-293. https://doi.org/10.1111/j.1744-6570.1993.tb00874.x

Van der Post, W.Z., De Coning, T.J., \& Smit, E.V. (1997). An instrument to measure organisational culture. South African Journal of Business Management, 28(4), 147-168. https://doi.org/10.4102/sajbm.v28i4.800

Veldsman, T. (2012, October). The growing cancer endangering organisations: Toxic leadership. Paper presented at the Conference on Leadership in Emergin Countries presented by Department of Industrial Psychology and People Management, Faculty of Management, University of Johannesburg, Johannesburg.

Vreja, L.O., Balan, S., \& Bosca, L.C. (2016). An evolutionary perspective on toxic leadership. Management \& Economics Review, 1(2), 217-228.

Weaver, S.G., \& Yancey, G.B. (2010). The impact of dark leadership on organizational commitment and turnover. Leadership Review, 10(Summer), 104-124.

Webster, V., Brough, P., Daly, K., \& Myors, B. (2011). Consequences of toxic leadership behaviours: A qualitative investigation. Retrieved from https://www.anzam.org/ wp-content/uploads/pdf-manager/563_ANZAM2011-314.PDF

Zangaro, G., Yager, K., \& Proulx, J. (2009). Recognizing and overcoming toxic leadership. Retrieved from http://www.rnjournal.com/journal_of_nursing/recognizing _ and overcoming toxic leadership.htm 